\title{
Human factors of digitalized mobility forms and services
}

\author{
Alexandra Millonig ${ }^{1}$ and Sonja Haustein ${ }^{2 *}$
}

In the light of pressing challenges like climate change, urban congestion, air and noise pollution and traffic safety there are numerous efforts aiming at reducing car traffic and shifting road users to more sustainable forms of mobility. In this respect, digitalization and technology developments offer new opportunities to support this development. The envisioned solutions range from increasing the energy efficiency of vehicles as well as their usage through pooling and sharing options, the introduction of a growing variety of micro vehicles for bridging last mile gaps (e.g. electric scooters, monowheels), or multimodal information and ticketing services to encourage changing monomodal car use. These solutions are based on a high-tech vision of future mobility composed of highly efficient automated vehicles of different shapes and sizes running on green and renewable energy, where people take responsibility and informed transport decisions resulting in a sustainable and just modal split, and where all road users share public space equitably and in harmony. Needless to say, that in this vision every individual is provided with at least the same or even higher "anywhere, anytime" transport guarantee as well as more personal comfort, all at a reasonable price.

Of course, most experts agree that this perfect future will most probably be hard if not impossible to reach, as scenario studies comparing less perfect and partly conflicting scenarios show [1], but in general it is wise to aim high for reaching at least the closest possible scenario near this vision. However, experiences with technology-boosted increase of vehicle efficiency and newly introduced sustainable sharing and pooling services show that technologies and digitalized services achieve significantly less impact than assumed, and it becomes more and more apparent that technological development will not suffice in reaching a sustainable and fair mobility system [2]. One of the main

\footnotetext{
* Correspondence: sonh@dtu.dk

${ }^{2}$ Technical University of Denmark, Kgs. Lyngby, Denmark

Full list of author information is available at the end of the article
}

reasons for this frequent underperformance is that in many cases users of new technologies and services do not behave as expected, which results in rebound effects [3, 4]. Rebound effects occur because humans tend to assign costs of any kind (e.g. money or time) to fairly stable mental accounts [5]. That means that savings in a specific category get reinvested, resulting in an increase of demand compensating the savings. As an example, the transport system has been seeing increasing amounts of distances travelled per person during the last decades, but at the same time travel time budgets remain more or less on the same level, indicating that saved time is simply reinvested in longer distances [6]. Another example is the fact that increasing energy efficiency in cars leads to consumers buying larger cars and hence compensating the gain [7] or the indication that consumers buying "green" vehicles start driving more as they perceive it as less harmful [8]. For more recent digitalization developments, similar effects become suspected. While at present Mobility as a Service (MaaS) is seen by many as significant chance to shift people from private cars to other, more sustainable modes, some studies already hint to a plausible oppositional impact: multicar-households are less interested in MaaS than households with only one or no car, suggesting that MaaS may hardly be used as replacement of a second or third car in the household, but rather put more people from public transport into the more flexible and comfortable shared car, thus increasing the amount of vehicles on the streets [9]. Similarly, automated cars that seem to promise positive environmental effects may actually increase travel demand by encouraging people to move further away from the city center or work place due to a better utilization of travel time [10].

\section{Factoring in the human factor}

Examples like these suggest that it is worth to take a closer look on seemingly irrational mobility behaviours to avoid fallacies in the assumed effect of new services. 
Especially the increasing digitalization and incremental automation of vehicles and services, bearing highly promising opportunities to pave the way for a more sustainable and equitable mobility future, should be thoroughly rechecked from the perspective of behavioural phenomena. Such an approach complementing product and service development is vital for minimizing undesired or even backfiring effects of innovations that jeopardize the aspired vision for the overall mobility system, and it should not be limited to mere questions of "user acceptance".

However, what makes the consideration of Human Factors during the development and implementation of new digitalized solutions difficult, is that individuals often find it hard to imagine a hypothetical situation and their most probable reaction to it, limiting the insights that can be expected from stated preference (SP) designs. On the other hand, there are only few studies having the chance to observe behavioural effects and collect revealed preferences (RP) regarding already implemented services or long-term experiments. Consequently, the assessment of Human Factor effects requires different approaches at different stages of developing a new digitalized service. This Topical Collection presents a wide range of approaches to grasp the Human Factors affecting the impact of technological improvements and digitalized services, spanning from analysing field experiences and psychosocial perspectives from actual users of a system or experimental users within a Living Lab, to more hypothetical explorations of personal dispositions and expressed needs in view of unfamiliar or future services.

The first paper, authored by Adelé and Dionisio [11] provides hands-on experience from a "smart" carpooling app that turns out to be less smart than expected. Based on the analysis of chat protocols, trip refusal information and qualitative interviews with users, practical limitations and psychosocial barriers of the app are identified. Part of the limitations are caused by the "smart matching" function of the app. The app uses mobility habits to predict future trips and to propose relevant matches. This procedure causes misunderstandings as it often remains unclear to the user whether proposals are made by users or the system. Additionally, the high number of bad matches leads to discomfort both for the one who refuses a trip and the one whose offer is refused. Due to the complexity of the matching task and the limitation of the system, the authors suggest giving a smaller role to the system and a stronger role to the end-user. Another conclusion of the study is that intelligent systems cannot replace human relations in the process of building trust. This is concluded from the extensive use of the chat function before a ride and the content analysis of the chats. The study also reveals that carpooling is socially and emotionally demanding as there is high insecurity about the appropriate behaviour at different stages of the journey (e.g. What to do after a refusal? Is it better to talk or not to talk in the car? Who should initiate the next shared ride?), which could be addressed in a best practice guide. Despite the outlined difficulties, users perceive carpooling as a good solution and positive experience, which should motivate to implement improvements as suggested in the paper.

In the second paper, Sjöman et al. [12] report experiences from a Living Lab in which economic information and incentives were tested with regard to their ability to motivate sustainable mobility transitions. The three tested interventions include: 1) making costs of participants' car use transparent; 2) providing cheaper access to public transport during off-peak hours; 3) economic rewards for cycling. Nine car-owning participants who varied in sociodemographics, access to public transport and commuting mode were included in the study. During the 6-month study period, participants used a GPS-tracker app that collected individual travel information. Additionally, in-depth interviews with participants were conducted before, during, and after the Living Lab. During these interviews, participants' travel behaviour and related attitudes, needs, and perceptions were explored. Participants were confronted with the yearly total costs from driving their own car compared with the hypothetical costs of a car sharing service. Generally, the differences were perceived as much too low to motivate a shift from private car ownership to car sharing. The results support findings from previous research showing that the perceived freedom, autonomy and convenience of car use are difficult to meet with alternative modes and services. The reason that alternative transport modes are often perceived as expensive could partly be explained by "unfair" comparisons people make, not taking the car's full costs into account. The tested incentives for off-peak public transport use and cycling showed rather minor effects but the idea of rewarding cycling was mostly seen positive and could be effective in case of higher rewards as has already been demonstrated in an ebike commuting study in the Netherlands [13].

The third paper by Chee et al. [14] examined the potential use of different automated vehicle (AV) services, or more specifically, which factors affect the willingness to pay for their use. Apart from a first/last mile automated bus service that was already in operation as part of an AV trial in Sweden, on-demand personalized AV services and demand responsive shared AV services were considered. Study participants were potential users of the service who lived, worked or studied in the area of the trial and about half of them had already taken at least one automated bus ride. A survey collected data on socio-demographics and commuter mode choice, perceptions about different AV attributes (e.g. safety, comfort, travel time) as well as the amount of money people 
were willing to pay for the three services on top of a regular monthly public transport pass. The survey showed that people who had tried the AV service perceived it as safe and comfortable and were more willing to pay for future on-demand personalized AV services. Results of separate structural equation models moreover showed that expectations towards each type of AV service differed. Apart from service quality expectations, AV rider experience, and income, willingness to pay differed by commuter mode choice and knowledge about AV technology: People who walked for daily trips perceived a negative ride comfort of AV services; people with greater knowledge about AV technology were more sceptical about AV safety.

While the first three studies were at least partly based on actual user experience, the two remaining papers deal with the acceptance and potential use of future mobility solutions based on descriptions of these services.

König and Grippenkoven [15] focus on the relevance of different service attributes for the adoption of a ridepooling service. Based on discrete choice experiments, they find that all considered attributes (fare, walking distance to the pick-up point, time of booking in advance, shift of departure time, travel time, information) significantly affected the choice of the service but that the appraisal of them differed depending on the trip purpose: In case of a doctor's appointment, people were, for instance, more sensitive to a shift of departure time, an increase of travel time and walking distance to the pick-up point than were people for a shopping trip. Correspondingly, also the respondents' willingness to pay for an improvement in the service attributes differed depending on the trip purpose. Based on the results, the authors suggest concrete recommendations for service providers, for example to avoid shifts of departure time shortly before the trip by freezing the time window for bookings. They expect further insights from considering additional trip purposes and differences in the assessment of service attributes based on sociodemographic variables.

The last paper by Winter et al. [16] identifies potential user groups of shared and automated mobility services. It is based on stated choice experiments, in which participants can choose between free-floating car-sharing, shared automated vehicles, private vehicles, busses, or taxis under a systematic variation of different time and cost related parameters. Based on latent class modelling, three user classes were identified: "Brisk Sharers" mainly young adults who prefer shared modes over private modes and are very sensitive towards increases of travel time. "Public Transport Enthusiasts" - typically public transport commuters who are less time but more price sensitive. They are typically older but prefer shared modes to the same extent as brisk sharers. In contrast to that, "Car Captives" are current car commuters who dislike shared modes, tend to be older and less educated. The paper moreover shows that current car commuters are open for shared services but not for automation. While intermodal commuters, combining PT and the car, are most open to shared (automated) services, people commuting solely with $\mathrm{PT}$ are least open. In line with the results by Chee et al. [14], the study thus shows that current commuter mode choice is a relevant predictor of the acceptance of new car-based mobility services.

\section{Learnings and recommendations}

The examples given in this Topical Collection provide valuable knowledge for an improved consideration of the Human Factor perspective in digitalized mobility developments. Several learnings can be drawn from the contributions, which can help to achieve the originally intended impact of digitalized services.

One important insight is that individuals have to deal with a lot of insecurities when using a new or unfamiliar system, which can limit or even hinder the success of the service. Many of these insecurities concern the appropriate interaction with other users, others concern the system itself if it appears like a black box to the user and it is not clear what it actually does. Service developments should therefore ensure sufficient transparency of the system to help people understand its actions, and to clearly define the contribution of the system to the user's decision basis. Similarly, systems supporting interactions between users should consider providing simple guidelines to suggest social rules and facilitate the exchange.

In many cases, the potential success of a service is estimated along its ability to help users in comparing different mobility options based on factual attributes like travel time, costs, potential incentives, and other measurable attributes. Findings within this Topical Collection however show, that personal motives and subconscious values people attribute to a specific mode or a trip purpose can easily override a "rational" decision. For future developments, it might therefore be advisable to pay more attention to symbolic and affective motives of mode choice than focusing solely on functional aspects. Approaches to decipher the emotional meaning behind reported preferences can help to shape a sustainable mobility alternative along such subconscious qualities and raise its acceptability.

From the methodological viewpoint, the contributions in this Topical Collection provide valuable experiences in exploring Human Factors, which is very useful for choosing the appropriate approach for specific questions. One take-away is that the more time people have to get familiar with a new service, the more accurate assessments of its applicability in the personal environment of the respondents can be achieved. The long-term 
approach of Living Labs is a beneficial experimental environment to observe changes in attitudes and behaviours. Also, systematic sampling can be helpful, as individuals who had at least some experience with the subject matter of the research can provide more reliable responses than a best guess from an unexperienced respondent. Moreover, methods identifying different behaviour profiles instead of targeting a heterogeneous mass of users can better explain differences in behaviour responses and related impact, and help to adjust services to the needs of potential user groups $[17,18]$.

Finally, we should also be aware of the fact that $\mathrm{Hu}$ man Factor phenomena are not limited to users. Humans operate at every level of the mobility system researchers, developers, providers, decision makers and although they may have more factual insights into the complex nature of mobility than the average citizen, no one is safe from interfering misperceptions and personal motives. But by widening our horizon beyond technological progress through understanding ourselves and others, we are likely to achieve more power in shaping the mobility future instead of having to deal with dead ends and sunken costs.

Authors' contributions

The authors read and approved the final manuscript.

\section{Competing interests}

The authors declare that they have no competing interests.

\section{Author details}

${ }^{1}$ AIT Austrian Institute of Technology, Vienna, Austria. ${ }^{2}$ Technical University of Denmark, Kgs. Lyngby, Denmark.

Published online: 06 July 2020

\section{References}

1. Vallet, F., Puchinger, J., Millonig, A., Lamé, G., \& Nicolai, I. (2020). Tangible futures: combining scenario thinking and personas - a pilot study on urban mobility. Futures, 117(2020), 102513.

2. Lorenz, F., Millonig, A., Richter, G., \& Peer, S. (2020). Mobility budgets as a sufficiency approach in transport policy. In Share the road programme annual report 2019, UNEP Open Access. (forthcoming).

3. Santarius, T., Walnum, H. J., \& Aall, C. (2016). Rethinking climate and energy policies. New perspectives on the rebound phenomenon. Cham: Springer International Publishing https://doi.org/10.1007/978-3-319-38807-6.

4. Otto, S., Kaiser, F. G., \& Arnold, O. (2014). The critical challenge of climate change for psychology. European Psychologist, 19(2), 96-106 https://doi.org/ 10.1027/1016-9040/a000182.

5. Ranyard, R. (Ed.). (2018). Economic psychology. Hoboken: British Psychological Society \& Wiley.

6. Cervero, R. (2011). Going beyond travel-time savings: an expanded framework for evaluating urban transport projects (report). Washington, DC: World Bank (published 27 June 2012) Report Number 70206. Retrieved 25 May 2020. http://documents.worldbank.org/curated/en/466801468178764085/pdf/702 060ESWOP1200s0inOUrban0Transport.pdf.

7. Ajanovic, A., Schipper, L., \& Haas, R. (2012). The impact of more efficient but larger new passenger cars on energy consumption in EU-15 countries. Energy, 48(1), 346-355.

8. Haustein, S., \& Jensen, A. F. (2018). Factors of electric vehicle adoption: a comparison of conventional and electric car users based on an extended theory of planned behavior. International Journal of Sustainable Transportation, 12(7), 484-496.
9. Liljamo, T., Liimatainen, H., Pöllänen, M., Utriainen, R., \& Viri, R. (2020). Potential user groups of mobility as a Service in Finland. In A. M. Amaral, L. Barreto, S. Baltazar, J. P. Silva, \& L. Goncalves (Eds.), Implications of mobility as a service (MaaS) in urban and rural environments: emerging research and opportunities (pp. 51-81). Pennsylvania: IGI Global https://doi.org/10.4018/ 978-1-7998-1614-0.ch003.

10. Nielsen, T. A. S., \& Haustein, S. (2018). On sceptics and enthusiasts: what are the expectations towards self-driving cars? Transport Policy, 66, 49-55.

11. Adelé, S., \& Dionisio, C. (2020). Learning from the real practices of users of a smart carpooling app. European Transport Research Review, 12, 39 https://doi. org/10.1186/s12544-020-00429-3.

12. Sjöman, M., Ringenson, T., \& Kramers, A. (2020). Exploring everyday mobility in a living lab based on economic interventions. European Transport Research Review, 12, 5 https://doi.org/10.1186/s12544-019-0392-2.

13. de Kruijf, J., Ettema, D., Kamphuis, C. B., \& Dijst, M. (2018). Evaluation of an incentive program to stimulate the shift from car commuting to e-cycling in the Netherlands. Journal of Transport and Health, 10, 74-83.

14. Chee, P. N. E., Susilo, Y. O., Wong, Y. D., et al. (2020). Which factors affect willingness-to-pay for automated vehicle services? Evidence from public road deployment in Stockholm, Sweden. European Transport Research Review, 12, 20 https://doi.org/10.1186/s12544-020-00404-y.

15. König, A., \& Grippenkoven, J. (2020). Modelling travelers' appraisal of ridepooling service characteristics with a discrete choice experiment. European Transport Research Review, 12, 1 https://doi.org/10.1186/s12544019-0391-3.

16. Winter, K., Cats, O., Martens, K., et al. (2020). Identifying user classes for shared and automated mobility services. European Transport Research Review, 12, 36 https://doi.org/10.1186/s12544-020-00420-y.

17. Haustein, S., \& Hunecke, M. (2013). Identifying target groups for environmentally sustainable transport: assessment of different segmentation approaches. Current Opinion in Environment Sustainability, 5(2), 197-204.

18. Markvica, K., Millonig, A., Haufe, N., \& Leodolter, M. (2020). Promoting active mobility behavior by addressing information target groups: the case of Austria. Journal of Transport Geography, 83, 1-13.

\section{Publisher's Note}

Springer Nature remains neutral with regard to jurisdictional claims in published maps and institutional affiliations.

\section{Submit your manuscript to a SpringerOpen ${ }^{\circ}$ journal and benefit from:}

- Convenient online submission

- Rigorous peer review

- Open access: articles freely available online

High visibility within the field

- Retaining the copyright to your article

Submit your next manuscript at $>$ springeropen.com 